Ramos, R.G.; Moura, V.M.C.; Macêdo, E.M. Perspectivas do desenvolvimento turístico de base local em Simplício Mendes (PI). Revista Brasileira de Ecoturismo, São Paulo, v.6, n.2, mai/jul2013, pp.572-585.

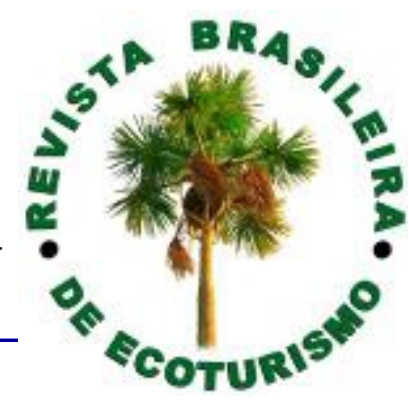

\title{
Perspectivas do desenvolvimento turístico de base local em Simplício Mendes (PI)
}

\author{
Prospects of the touristic development of locally-based in Simplício Mendes \\ (PI, Brazil)
}

\section{Ricardo Gomes Ramos, Valéria de Morais Costa Moura, Ermínia Medeiros Macêdo}

\section{RESUMO}

A presente pesquisa pretende demonstrar as possibilidades de desenvolvimento turístico no município de Simplício Mendes, por meio da produção do mel, como forma de caracterizar e organizar o trabalho das famílias apicultoras, baseado no desenvolvimento local e na regionalização do turismo. Os procedimentos metodológicos adotados foram a revisão teórica de turismo rural, agroturismo, desenvolvimento local e geografia do turismo; pesquisa de campo (observação e entrevistas) com a comunidade de Simplício Mendes e membros da Cooperativa Mista dos Apicultores da Microrregião. Os resultados obtidos revelam que o agroturismo pode trazer benefícios para a região, mediante políticas de planejamento, de forma a caracterizar o local como um centro turístico de escala aos fluxos que utilizam a rodovia BR 020 (Brasília/Fortaleza) ou em busca do atrativo Parque Nacional da Serra da Capivara, localizado no município de São Raimundo Nonato, distante cerca de 100 quilômetros do local.

PALAVRAS CHAVE: Agroturismo; Desenvolvimento Local; Apicultura; Piauí.

\section{ABSTRACT}

This paper aims to demonstrate possibilities of tourism development in Simplicio Mendes (PI, Brazil) through the honey production as a way to characterize and organize the work made by the families whom produce honey based on local development and the regionalization of tourism. The methodological procedures adopted were the theorical review about agritourism, rural tourism, local development and geography of tourism; field research (observation and interviews) with the community of Simplício Mendes and members of the beekeepers' micro region cooperative. The results observed indicate that the agritourism activity may aggregate benefits to the region by planning policies in order to characterize the place as a scale tour center by the users of the highway BR 020 (Brasília / Fortaleza) or tourists on their way to Serra da Capivara National Park, in São Raimundo Nonato, far from Simplício Mendes about 100 kilometers.

KEYWORDS: Agritourism; Local development; Apiculture; Piauí. 


\section{Introdução}

No Brasil, a prestação de serviços do turismo no meio rural, quando realizada por associações e cooperativas, tem possibilitado que núcleos de pequenos produtores passem a negociar seus produtos com o mercado de forma mais justa, observando-se ainda o advento dos APL - Arranjos Produtivos Locais, por estarem baseados em uma identidade de coletividade, portanto desempenhando importante papel no desenvolvimento local (JORGE, 2009).

Os arranjos produtivos locais, portanto, desenvolvem atividades em conjunto que irão conduzir a realidade de um único produto e, quando aplicados ao turismo relacionam-se à estrutura que direta ou indiretamente participa da organização do produto (THOMAZI, 2006).

Logo, o cooperativismo e o associativismo são de suma importância para o desenvolvimento do agroturismo no Brasil que ocorre em várias regiões do país, ocasionando um preparo individual e coletivo de forma rentável, dependendo de uma ação conjunta e organizada, estabelecida por diversos mecanismos, que conferem-lhe uma vantagem competitiva especifica distinta a de um grupo não estruturado ou organizado.

A proposta do presente trabalho trata da caracterização da produção de mel e seus derivados no município de Simplício Mendes (Piauí, Brasil) oriunda da formação de uma associação, por meio da construção de um entreposto para a comercialização de mel por parte do padre Geraldo Geroen, desde o ano de 1994. Sabendo que a produção de mel na região é parte integrante da renda familiar, busca se compreender de que forma tal cultura pode ser aproveitada para a prática do agroturismo na perspectiva do turismo de base local, no intuito de se proporcionar experiências de desenvolvimento local por meio de cooperativismo ou associativismo.

Para tanto, leva-se em consideração a localização do município e seu entendimento como um centro turístico de escala, bem como a capacidade do produto turístico enquanto vetor de agregação de valor à produção agrícola, estimulando o fortalecimento da cadeia produtiva local.

\section{Considerações teóricas sobre o turismo de base local e o agroturismo}

O turismo de base local demonstra ser uma forma plausível ao desenvolvimento socioeconômico de determinada localidade por possibilitar a geração de emprego e renda das comunidades onde se encontra inserido, com consequente valorização de seus aspectos socioculturais. Nessa ótica, sua composição deverá ocorrer de forma a atender os princípios da sustentabilidade, pois como observam Faria e Carneiro (2007, p.19):

O antagonismo entre crescimento econômico e sustentabilidade é próprio de uma sociedade capitalista, na qual a preocupação em garantir a continuidade do processo de industrialização, afetada pelo esgotamento, esbarra em uma lógica de mercado, alheia a estratégias de médio e longo prazo que priorizam benefícios sociais e ambientais em oposição à acumulação de renda e consequentes disparidades econômicas. 
Entende-se, portanto, que a sustentabilidade para o turismo é de grande importância no sentido de trazer benefícios para a comunidade local, sendo esta, quando atrelada à atividade turística, chamada de turismo comunitário ou de base local, cuja definição permeia a idéia de que:

\begin{abstract}
O influenciador de desenvolvimento regional diversificado, com inovações constantes em função de novas exigências da demanda e da competitividade dos mercados, conceitua-se turismo comunitário (ou de base local), que é toda forma de organização empresarial sustentada na propriedade e na autogestão sustentável dos recursos patrimoniais comunitários, de acordo com as práticas de cooperação e equidade no trabalho e na distribuição dos benefícios causados pela geração de produtos turísticos (MALDONADO, 2009, p.31).
\end{abstract}

Sendo assim, o turismo comunitário ou de base local é aquele cujas sociedades locais possuem controle efetivo sobre seu desenvolvimento e gestão por meio do envolvimento participativo. Dessa forma, o turismo de base local trabalha a atividade turística de modo integrado e participativo, considerando a valorização dos elementos naturais e culturais, no sentido de contribuir para agregar valor ao produto e aos serviços, havendo assim um comprometimento com a produção e a prestação de serviços, beneficiando e possibilitando a verticalização do produto (RUSCHMANN, 2002).

O turismo de base local passa a ser referenciado não somente no sentido valorativo da escala espacial, mas como alternativa ao padrão dominante de desenvolvimento. Estabelecer perspectivas de desenvolvimento faz do turismo uma atividade articulada ao desenvolvimento local apresentando características genuínas, pela inserção de novos produtos e, com isso, a geração de novos empregos e investimentos para a comunidade receptora.

A existência de estruturas de apoio a nível local poderão facilitar as informações, as necessidades do mercado, a busca de suporte técnico para o desenvolvimento de projetos e programas, com o objetivo de trabalhar a atividade turística de modo integrado e participativo, reforçando a cooperação produtiva e a valorização dos elementos naturais e culturais.

De modo geral pode-se dizer que a cultura permeia todos os segmentos de turismo, uma vez que o turista é atraído pelo diferente, desde que lhe sejam garantidos conforto e segurança. Nesse sentido, o processo de desenvolvimento sustentável dependerá da participação e integração dos agentes sociais, que irão atuar como transformadores do seu próprio desenvolvimento, voltando-se para as atividades turísticas da localidade (DIAS, 2006).

No entanto, o cumprimento das condições de sustentabilidade é um importante problema político, econômico e ambiental uma vez que requer novas formas de encarar a natureza e o propósito do desenvolvimento e o papel dos indivíduos, do governo e do setor privado no desenvolvimento de futuros sustentáveis é uma preocupação que está cada vez mais na dianteira da análise do turismo (HALL, 2001). 
Dentre os diferentes modelos do turismo de base local no Brasil, tem-se o agroturismo como uma das segmentações que mais demonstra resultados favoráveis à inserção de comunidades no processo de desenvolvimento socioeconômico por meio da atividade turística. Por agroturismo, entende-se a oferta do produto em que o turista passa o dia no meio rural, podendo desfrutar de diferentes atrativos como a participação nos trabalhos produtivos (ARAÚJO, 2000).

Surgido na Europa, na década de 1960, o agroturismo desenvolveu-se principalmente na Itália, pelo advento da cultura e produção da uva e seus derivados, embora ocorra em vários países com diferentes denominações e características (TULIK, 2003).

Beni (2004, p.428) define o agroturismo como,

\begin{abstract}
O deslocamento de pessoas a espaços rurais, em roteiros programados ou espontâneos, com ou sem pernoite para fruição de cenários e observação, vivência e participação nas atividades agropastoris, ainda afirma que o que difere o agro turismo do turismo rural é a produção agropastoril em escala econômica, que representa a maior fonte de rendimento da propriedade e o turismo, receita complementar; o segundo é que as próprias atividades agropastoris constituem em si mesmas o principal diferencial turístico.
\end{abstract}

A experiência agroturística proporciona ao turista um contato enriquecedor com a cultura do local, de forma a valorizar e preservar as tradições locais, gerando renda por meio do aproveitamento da capacidade humana em diferentes meios de produção agrícola, fazendo com que espaço rural não seja mais pensado apenas como um lugar produtor de mercadorias agrárias, mas também como um espaço propício à inclusão do turismo e do lazer, gerando possibilidades para que famílias de agricultores aprendam a produzir serviços, de forma a melhorar a qualidade de vida das pessoas (ARAÚJO, 2000).

Destaca-se, contudo que, qualquer iniciativa regional ou local para o desenvolvimento do turismo no meio rural, deve se iniciar por um zoneamento econômico e ecológico do espaço rural, seguido de uma descrição dos principais produtos turísticos e análise de sua demanda atual e potencial, do ordenamento territorial das atividades produtivas e do cadastramento de agricultores em conformidade ao interesse e potencial de inserir o agroturismo como forma complementar de incremento de renda.

\title{
Experiências e características do turismo no meio rural brasileiro
}

A atividade do turismo no meio rural brasileiro foi iniciada no ano de 1986, no município de Lages, em Santa Catarina. Durante a década de 1990, o turismo rural se estendeu para outras regiões do Brasil, como foi o caso do município de Venda Nova do Imigrante, na região central do Espírito Santo que, fundamentado em modelos europeus passou inicialmente a comercializar produtos, com posterior inserção de visitação de meios produtivos locais (ZIMMERMANN, 1996; TULIK, 2003). 
No Brasil, tem-se buscado por locais que possuam um diferencial, como a valorização de áreas naturais e culturais, e ideias que possibilitem famílias a adquirir conhecimento e melhoria das condições de vida, por meio do turismo. No Estado do Paraná, por exemplo, a implementação do turismo rural vem sendo estimulada como uma forma de caracterizar produtos e roteiros turísticos, diversificando a oferta dos destinos turísticos. De acordo com informações da SETUR Paraná (2007, p.4),

\begin{abstract}
cerca de $28 \%$ dos roteiros turísticos que estão sendo comercializados pelas agências de turismo são de Turismo Rural, portanto, a construção do Programa de Turismo Rural visa aproveitar a vocação agropecuária do Paraná, uma vez que a ocupação de grande parte do seu território caracterizou pela chegada de agricultores de várias partes do Brasil e do exterior. Esta ocupação se intensificou no final do século XIX e possibilitou construir um Estado que hoje é líder na produção agropecuária, havendo uma diversidade de produtos que se destinam à alimentação bem como para a produção de matéria-prima para as indústrias nacionais.
\end{abstract}

A ideia do programa, conforme exposto pela SETUR Paraná, é gerar possibilidades para que as famílias de proprietários e trabalhadores, das unidades rurais aprendam a utilizar a produção das fazendas, as paisagens serranas, a cultura local, a hospitalidade do povo interiorano e a diversificada culinária regional, como atrativos turísticos da região. Tulik (2003, p.59) afirma que,

no Brasil, assim como aconteceu em vários países, a busca por áreas rurais é antiga. Difícil, e também desnecessário, precisar momentos e locais exatos, mas os deslocamentos aparecem registrados em obras literárias,seja na forma de temporadas no campo,seja como piqueniques. Buscava-se a natureza, a tranquilidade e o bucolismo, ou seja, o oposto ao urbano. Pequenas cidades eram, e ainda são procuradas pelo mesmo motivo.

O turismo no meio rural, portanto, demonstra potencial de crescimento no mercado turístico e, por esse motivo, as atividades turísticas em meio rural vem sendo incentivadas, a partir do início do século XXI, pelo governo federal brasileiro como forma complementar de renda às comunidades inseridas no programa da agricultura familiar, citando o exemplo da Rede TRAF (Turismo Rural na Agricultura Familiar) apoiada pelo Ministério do Desenvolvimento Agrário em parceria ao Ministério do Turismo brasileiro (BRASIL, 2008; SETUR PARANÁ, 2007).

A atividade turística na agricultura familiar, embora recente, vem ganhando espaço e crescendo no meio rural. A notoriedade dessas informações tem chamado atenção de varias áreas e setores. No Brasil foram criados programas de desenvolvimento do turismo no espaço rural, como observado:

O Ministério do Desenvolvimento Agrário junto com o Ministério do Turismo (MTUR) criaram o PNTRAF Programa Nacional de Turismo Rural na Agricultura Familiar, que visa promover o desenvolvimento rural sustentável, através da implantação e fortalecimento das atividades turísticas pelos agricultores familiares, integrando os arranjos produtivos locais, uagregando renda e ge- 
rando postos de trabalho no meio rural, com conseqüente melhoria das condições de vida (REDETRAF, 2012, s/p)

Como exposto, o turismo rural e o agroturismo apresentam alternativas para as pequenas famílias agricultoras, no sentido de melhorar seu nível de vida e manter a população no espaço rural, exigindo, contudo, que as comunidades rurais se articulem para favorecer o incremento ao segmento, identificando-se por meio da estruturação da oferta turística para que assim possam fortalecer o produto e atender a demanda. Desse modo, Moletta (2000, p.39) considera que,

\begin{abstract}
o proprietário tem procurado fazer mudanças nas associações locais e nos meios de produção, para atender a demanda que busca pela tranqüilidade e qualidade de vida. O turismo rural, quando desenvolvido em uma propriedade rural, também pode criar inúmeras oportunidades para a comunidade em seu entorno.
\end{abstract}

Dessa forma, o sentido dos termos turismo rural e agroturismo tratam de uma atividade que proporciona o envolvimento do turista com a comunidade local, gerando experiências educativas com os fenômenos naturais e culturais, devendo estar atreladas ao planejamento do turismo no espaço rural, no intuito de não desarticular o crescimento da comunidade receptora em tempo de agregar a qualificação dos atrativos e serviços turísticos, como defendem Almeida; Rield (2000, p.164),

\begin{abstract}
Para que um empreendimento do turismo no espaço rural tenha sucesso é desejável que se instalem agências e operadoras de turismo locais, que caracterizem melhor os produtos oferecidos, que estabeleçam um vinculo mais estreito com os pequenos agricultores, que sejam mais sensíveis aos potenciais e problemas locais e que explorem adequadamente os diferentes nichos de mercado.
\end{abstract}

Nesse sentido, o agroturismo carece de iniciativas de aperfeiçoamento dos serviços, sendo o associativismo uma das alternativas plausíveis a tal necessidade, por oportunizar o estreitamento das relações entre a sociedade organizada e 0 poder público. Para tanto, o associativismo deve ser incentivado por um organismo público ou associação organizada, fornecendo assistência técnica e administrativa. Outra forma de aperfeiçoar os serviços solicitados pelo desenvolvimento do agro turismo é o cooperativismo, caracterizado por uma forma de produção e distribuição de riquezas baseada em princípios como a ajuda mútua, a igualdade, a democracia e a equidade (SEBRAE PARANÁ, 2011).

Para que o cooperativismo seja eficiente no sistema econômico, é fundamental o crescimento da atitude pró-ativa dos agentes locais que se tornam sujeitos protagonistas do seu empreendimento, melhorando, assim, as condições de renda dos cooperados, bem como as condições de trabalho e a independência do trabalhador. A existência da cooperativa é um meio, para que um determinado nú- 
mero de indivíduos atinja objetivos específicos através de um acordo voluntário. Os pequenos produtores deverão ser orientados e incentivados para tornarem-se capacitados a resolver os problemas existentes na comunidade e assim, oferecer os serviços diferenciados aos turistas. As cooperativas agregam valor aos produtos tornando-os diferenciáveis no mercado de consumo.

\section{O município de Simplício Mendes (PI) e seu potencial para o turismo}

O município de Simplício Mendes possui 12.068 habitantes (IBGE, 2010) e está localizado na microrregião de Alto Médio Canindé, na região sudeste do estado do Piauí (Brasil). A sede municipal tem as coordenadas geográficas de 070 51' 14" de latitude sul, e 410 54'37" Oeste de Greenwich e localiza-se a 416 km da capital Teresina. Apesar de ser um município pequeno, é pólo em sua microregião, ofertando, numa escala regional, serviços diversos como o comércio. As atividades que contribuíram para o desenvolvimento econômico do município foram a pecuária e a extração de borracha de maniçoba, além do comércio varejista crescente. (MOREIRA; MAVIGNIER, 2007)

Seu potencial para o turismo é representado por manifestações populares como eventos e festejos e também por seu patrimônio edificado, dentre os quais a Igreja Matriz do Sagrado Coração de Jesus cuja construção aconteceu entre os anos de 1922 e 1923, a qual promove, no mês de maio a Festa do Divino e, entre os meses de junho e julho, os festejos do padroeiro, em conjunto as festividades do vaqueiro e a Praça Dr. Isaias Coelho, com a estátua de um cidadão Simpliciomendense de mesmo nome, considerado importante figura local pela colaboração ao desenvolvimento do município. Outro ponto de interesse para o turismo no município é o mirante do Morro da Cruz, o qual proporciona vista panorâmica do município e arredores.

Em relação ao potencial para o agroturismo, cita-se o trabalho desenvolvido pelo Padre Geraldo Gereon, o qual implementou a cultura de produção de mel a partir de 1994, fazendo dessa, importante atividade econômica colaborativa à região. A apicultura desenvolvida no município de Simplício Mendes é uma atividade em expansão, que vem proporcionando a melhoria do espaço agrário como alternativa de evitar o êxodo rural. A Figura 1 demonstra alguns dos recursos turísticos existentes na localidade.

Em aspectos turísticos regionais, Simplício Mendes localiza-se entre os municípios de Oeiras (a primeira capital do estado do Piauí, contando com importante potencial para o turismo cultural, cívico e arquitetônico) e São Raimundo Nonato, onde se localiza o Parque Nacional da Serra da Capivara (PNSC), com uma das maiores concentrações de pinturas rupestres do mundo (MOREIRA; MAVIGNIER, 2007). 


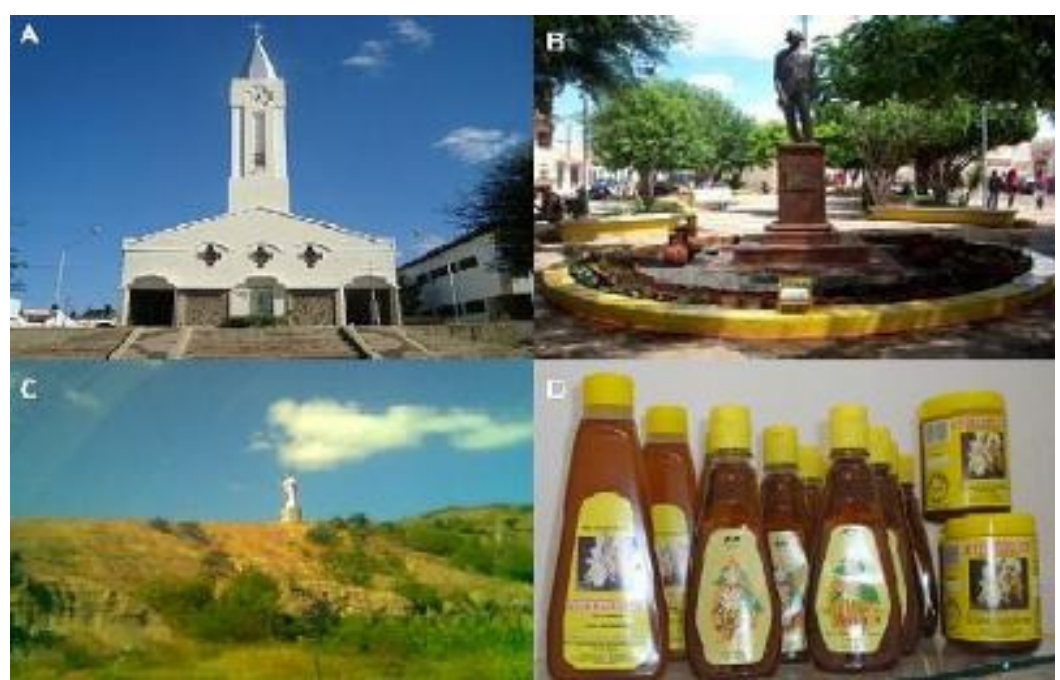

Figura 1: Alguns dos recursos turísticos de Simplício Mendes: A - Igreja Matriz do Sagrado Coração; B - Estatua de Isaías Coelho; C - Morro da Cruz; D - Produção de Mel. Fotos: autores.

Figure 1: Some of the tourist resources of Simplicio Mendes: A - Church of the Sacred Heart; B - Statue of Isaías Coelho; C - Morro da Cruz, D - Honey Production. Photos: by authors.

A Figura 2 demonstra que o município é cortado pela BR 020 (Brasília - Fortaleza) estando num raio de distância inferior a 200 quilômetros tanto da cidade de Oeiras como a de São Raimundo Nonato. Boullón (2002) afirma que o raio de influência de um centro turístico é calculado em até duas horas de distância-tempo, e, dessa forma, a cidade de Simplício Mendes pode, numa perspectiva de região, aproveitar o fluxo de visitantes tanto de Oeiras, como de São Raimundo Nonato.

É com o propósito de regionalização que pode haver o desenvolvimento do turismo em Simplício Mendes, levando em consideração sua demanda potencial em decorrência de sua localização geográfica, com a produção de mel relacionada ao agroturismo, já que, para Pearce (2003, p. 30), na análise do espaço turístico, deve-se levar em conta que: "aqueles viajando em rotas recreativas fazem uso de várias instalações turísticas ao longo do caminho, ainda que a área interveniente não se constitua no objetivo principal da viagem".

Para Beni (2006, p.125), o desenvolvimento do turismo em nível regional deve ocorrer como,

abordagens de desenvolvimento que permeiam todo o planejamento estratégico de regiões turísticas, sendo complementares entre si e capazes de incrementar o poder de atração de destinação, assim como os benefícios trazidos pela atividade turística aos seus municípios, tem-se a regionalização turística ou o processo de clusterização da destinação.

Já Boullón (2002, p.71) afirma que,

quando um sistema de planejamento turístico começa a operar, a primeira coisa que se deve fazer é definir um âmbito de ação em função da regionalização. Essa tarefa consiste em dividi-lo em partes, de acordo com uma série de critérios técnicos. 


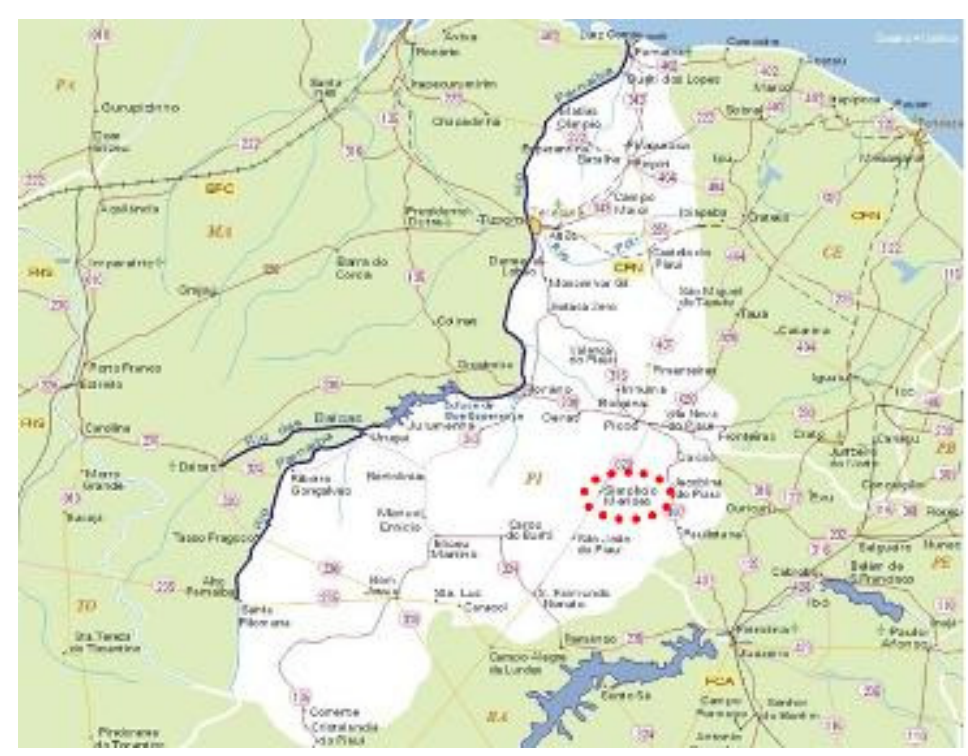

Figura 2: Mapa do Estado do Piauí com a localização de Simplício Mendes sinalizado em vermelho.

Fonte: Mapas Brasil, 2012.

Figure 2: Map of the State of Piauí with the location of Simplicio Mendes flagged in red.

Source: Maps Brazil, 2012.

Dessa forma, tem-se a regionalização do turismo como importante fator de construção de motivação à visitação em Simplício Mendes, uma vez que Bahl (2004, p.31) afirma que,

nem todas as localidades congregam atrativos turísticos em quantidade suficiente para se desenvolverem como centros de recepção, dependendo, por vezes, de se trabalhar com os existentes no seu entorno, permitindo-lhes ampliar o leque de opções para a prática de atividades e usufruto do turismo.

Sua localização, portanto, demonstra possibilidade de incremento econômico por meio do turismo, especialmente pela existência do Programa de Regionalização do Turismo, desenvolvido pelo Ministério do Turismo brasileiro, caracterizado como:

Um modelo de gestão de política pública descentralizada, coordenada reintegrada, baseada nos princípios de flexibilidade, articulação, mobilização, cooperação e sinergia de decisões. No conceito do Órgão estatal, regionalizar é transformar a ação centrada na unidade municipal em uma política pública mobilizadora, capaz de promover mudanças, sistematizar o planejamento e coordenar o processo de desenvolvimento local e regional, estadual e nacional, de forma articulada e compartilhada (Brasil, 2004, p.11).

Nesse sentido, o indivíduo que se desloca da capital do estado, Teresina, em direção ao Parque Nacional da Serra da Capivara, por via terrestre, obrigatoriamente passa pelo centro urbano de Simplício Mendes, dotando-o, em conformidade a classificação de Boullón (2002) como um centro de escala, já que sua localização geográfica o torna um ponto estratégico de acesso aos municípios de Oeiras e São Raimundo 
Nonato, pelas BR 316 (trecho Teresina - Regeneração), PI 236 (trecho Regeneração - Oeiras), PI 143 (trecho Oeiras - Simplício Mendes) e BR 020 (Simplício Mendes São Raimundo Nonato), como observado na Figura 3:

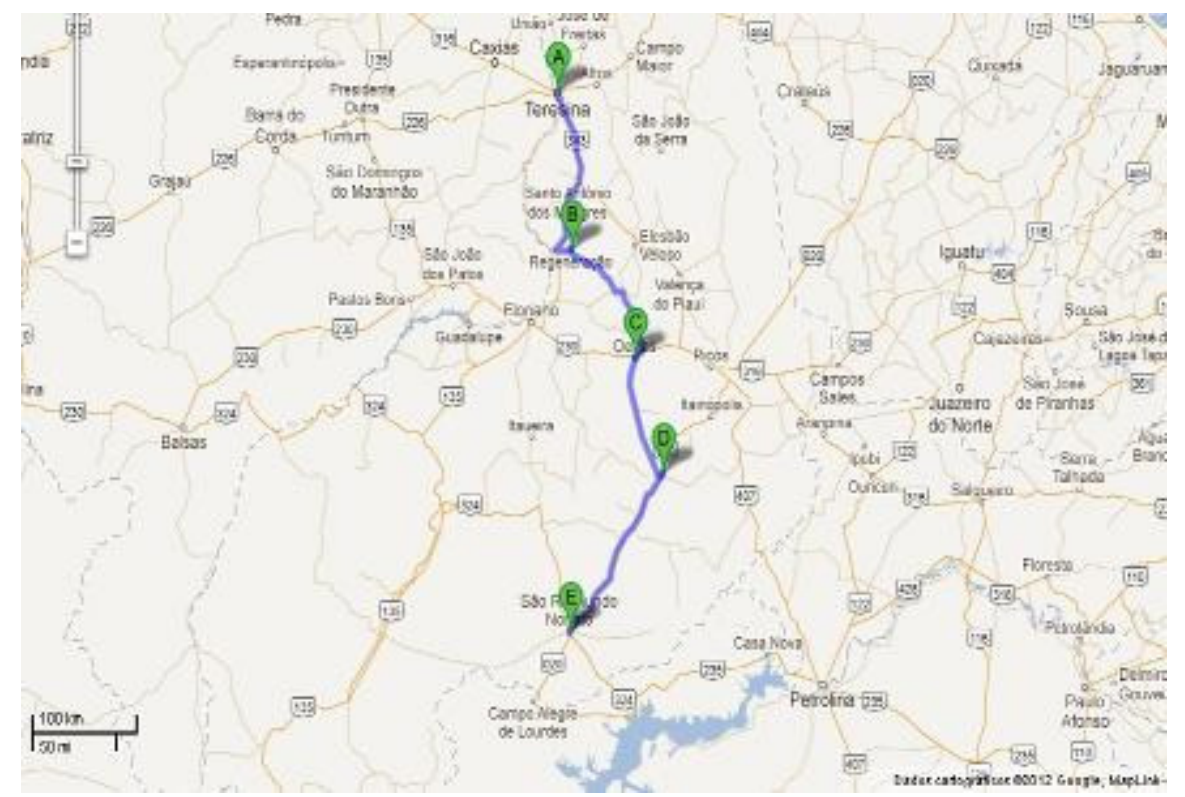

Figura 3: Detalhamento do deslocamento entre Teresina (A) e São Raimundo Nonato (E), passando pelas cidades de Regeneração (B), Oeiras (C) e Simplício Mendes (D). Fonte: Google Maps, 2012.

Figure 3: Breakdown of displacement between Teresina (A) and São Raimundo Nonato (E), through the cities of Regeneration (B), Oeiras (C) and Simplício Mendes (D). Source: Google Maps, 2012.

Nessa lógica, nota-se o potencial do turismo como uma alternativa econômica para a região, pois acrescido à produção do mel, o município de Simplício Mendes possui localização em um espaço que tem o acesso aos destinos considerados Pólos Turísticos do Estado do Piauí, portanto, fazendo com que o agroturismo possa ser acrescentado como uma forma de oportunizar e agregar valor ao espaço agrário, considerando a regionalização do espaço turístico.

\section{O entendimento da população acerca das possibilidades turísticas no município de Simplício Mendes (PI)}

Tendo conhecimento da importância na participação da população no processo de implantação do turismo em Simplício Mendes, foi realizada pesquisa com questionários semiestruturados a fim de verificar o entendimento e as expectativas da população quanto a possibilidade de inserir o turismo no município. A amostra foi composta por $1 \%$ da população total do município, dos quais, $80 \%$ do sexo feminino e $20 \%$ do masculino. A maioria dos entrevistados (70\%) possuem idade entre 15 a 24 anos, demonstrando um número grande de jovens que compõem sua população.

Quanto ao grau de escolaridade dos entrevistados, a maioria (44\%) possui ensino médio completo, seguido de $25 \%$ com ensino médio incompleto, $15 \%$ com ensino fundamental completo, $8 \%$ com ensino superior incompleto $5 \%$ com ensino superior completo e 
$3 \%$ com ensino fundamental incompleto, o que demonstra o acesso à instrução, portanto subentendendo maior colaboração a participação em novas atividades que venham a ser implantadas no município, como é o caso do turismo.

Quando questionados sobre o potencial para o turismo no município, a maior parte dos entrevistados lembrou da existência do Morro da Cruz (70\%), seguido da Praça Central (20\%), Produção de Mel (7\%) e Igreja Matriz (3\%), o que demonstra o desconhecimento, por parte da população, da possibilidade em se desenvolver o agroturismo, pelo advento da produção do mel, no município.

Sobre os eventos que existem na cidade, $62 \%$ dos entrevistados citam as festividades de fim de ano, portanto relacionada a visita a amigos/parentes, já que não existe nenhuma programação específica de natal e/ou ano novo no município, seguida pela Festa do Sagrado Coração de Jesus (23\%) e festa do Divino (5\%) e 10\% declararam não saber.

Em relação às expectativas para o turismo, a maioria dos entrevistados (80\%) acredita que o turismo traga benefícios ao município. Em relação ao preparo da cidade, aproximadamente $85 \%$ dos entrevistados dizem que a cidade não se encontra preparada para o turismo, enquanto cerca de $60 \%$ diz ter interesse em trabalhar com o turismo, portanto, demonstrando a receptividade de sua população para a inserção do turismo enquanto atividade colaborativa à economia da cidade.

Nota-se, portanto, que a população Simpliciomendense possui receptividade quanto a implantação do turismo no município, demonstrando interesse na participação do processo, contudo a necessidade de melhor entendimento, por parte dos entrevistados, do potencial agregado à região.

Tratando especificamente da produção de mel, foram realizadas pesquisas com questionários semiestruturados com a totalidade dos cooperados (12 indivíduos) os quais, em sua maioria (75\%), fazem parte da cooperativa desde sua abertura, em 1994. A pesquisa realizada com os membros da cooperativa foi no intuito de observar o posicionamento, quanto à experiência do trabalho realizado na cooperativa, e quanto às perspectivas que têm relacionadas ao turismo, as possibilidades do desenvolvimento do agro turismo na região.

Quando questionados sobre a possibilidade do mel ser visto como um elemento de identidade da região, as respostas demonstraram aspecto positivo, especialmente do entendimento do mel como uma fonte de renda para os agricultores, colaborando com sua subsistência, envolvendo cada vez mais os apicultores, reduzindo o êxodo rural além de ser um produto já reconhecido no mercado externo.

Para entender os aspectos de importância da produção de mel no município e microrregião de Simplício Mendes, buscou-se saber como a produção mudou na vida da família, manifestando que, com o mel, conseguiram investir nos estudos dos filhos, além de comprar móveis e imóveis com a renda adquirida pela comercialização, sendo esse uma fonte de renda complementar. Um dos entrevistados afirmou que "uma das melhores atividades aqui é a apicultura, porque existe o ano todo, e se não fosse o mel estaríamos em crise, pois é com a renda da produção que garantimos nosso meio de subsistência".

Em relação a possíveis melhorias na produção do mel, 90\% respondeu que gosta- 
riam de aumentar os apiários, ainda completaram que com mais apiários tem condições de aumentar a produção e 10\% demonstrou a importância em se conseguir veículo para o transporte de abelhas em consideração a época das floradas. Quanto ao questionamento sobre as limitações que encontram, todos responderam que sem chuvas há uma diminuição da florada nativa, para que as abelhas retirem o néctar e assim possam produzir o mel.

A compreensão obtida da pesquisa foi que a população acredita que o turismo pode trazer benefícios, porém estão desestimulados pela inexistência de políticas de desenvolvimento, e como forma de melhoria para a população, seria necessária a sensibilização turística, incentivos por parte governamental e do setor privado, garantindo que a cidade possa a vir a implantar a atividade em conformidade aos princípios do turismo de base local.

A população também acredita que o mel pode ser considerado uma identidade do município, mas os mesmos dizem não perceber os benefícios do mel na comunidade, o que demonstra falta de conhecimento da importância na produção de mel na localidade e, consequentemente, colaboração na divulgação e expansão do mercado de subprodutos do mel.

Os cooperados percebem como necessidades, a melhoria do trabalho para manter a meta anual da produção, dessa forma percebem-se como necessidades atuais a implantação de sistema de controle de produção e comercialização computadorizado, criação de site para divulgação dos produtos e trabalhos da COMAPI (Cooperativa Mista dos Apicultores do estado do Piauí), reforma do entreposto melhorando sua estrutura (piso adequado no depósito e área de homogeneização, aquisição de embalagens (tambores metálicos e baldes); aquisição de veículo novo; melhoria das estradas de acesso às comunidades; capacitação dos membros da Diretoria e Administrador na área administrativa e contábil.

\section{Considerações finais}

A inexistência de um conjunto de atrativos turísticos suficientemente responsáveis pela permanência com pernoite de um grupo de turistas não deve ser visto como um fator de exclusão da atividade turística na economia de uma localidade. A proximidade de Simplício Mendes aos Pólos Turísticos de Oeiras e São Raimundo Nonato é uma considerável justificativa de desenvolvimento do turismo no local, mesmo que apenas como um centro de escala.

Em aspectos gerais, para que o mel seja responsável pela busca do espaço geográfico de Simplício Mendes, torna-se inegável a elaboração de campanhas que visem a valorização desse elemento por parte de seus cidadãos. Para que isso aconteça, destaca -se a importância na construção de estratégias que contemplem a vocação turística inicial observada na cidade, com foco na produção de mel e sua profissionalização como elemento de competitividade, por meio de ações que incentivem a elaboração de subprodutos tais como a cera para depilação, geléias, bombons e biscoitos que, certamente, se expostas para venda, fará com que turistas e viajantes que utilizam a BR 020 as consumam.

Numa perspectiva de futuro, sugere-se a formatação de um roteiro turístico integrado, no intuito de agregar atratividade, incentivar a organização regional da oferta turís- 
tica e proporcionar a formatação de um cluster turístico com os municípios de entorno, em conformidade aos princípios do turismo de base local, bem como busca pela profissionalização da oferta turística nas propriedades rurais, sem descaracterizá-las, no intuito de proporcionar uma relação de troca de experiências, entre a comunidade local e o visitante consumidor.

\section{Referências bibliográficas}

ALMEIDA, J.A.; RIEDL, M. Turismo rural: ecologia, lazer e desenvolvimento. Bauru: EDUSC, 2000.

ARAÚJO, J.G.F. ABC do Turismo Rural. Viçosa: Aprenda Fácil, 2000.

BAHL, M. Agrupamentos Turísticos Municipais. Curitiba: Protexto, 2004.

BENI, M.C. Política e planejamento de turismo no Brasil. São Paulo: Aleph, 2006.

BENI, M.C. Análise Estrutural do Turismo. 10. ed. São Paulo:SENAC SP, 2004.

BOULLÓN, R. Planejamento do Espaço Turístico. Bauru: EDUSC, 2002.

BRASIL, Ministério do Desenvolvimento Agrário (2008). Programa de Turismo Rural na Agricultura Familiar [pdf]. Disponível em <http://www.territoriosdacidadania.gov.br/ o/875076>. Acesso em 07 dez. 2011.

BRASIL, Ministério do Turismo. Programa de Regionalização do Turismo: Roteiros do Brasil: Diretrizes Operacionais. / Ministério do Turismo, Secretaria Nacional de Políticas de Turismo. Brasília: Ministério do Turismo, 2004.

DIAS, R. Turismo e patrimônio cultural: recursos que acompanham o crescimento das cidades. São Paulo: Saraiva, 2006.

FARIA, D.S.; CARNEIRO, K.S. Sustentabilidade ecológica no turismo. Brasília: Editora Universidade de Brasília, 2007.

GOOGLE MAPS. Disponível em < http://maps.google.com >. Acesso em 27 jun. 2012.

HALL, C.M. Planejamento turístico: políticas, processos e relacionamentos. São Paulo: Contexto, 2001.

JORGE, R.R. Território, identidade e desenvolvimento: uma outra leitura dos arranjos produtivos locais de serviços no rural. Tese (Doutorado em Geografia Humana). Faculadde de Filosofia, Letras e Ciências Humanas - Universidade de São Paulo, 2009.

MALDONADO, C. O turismo rural comunitário na América Latina: gênesis, características e políticas. Turismo de Base Comunitária. Ed.01. Rio de Janeiro: Letra e Imagem (501 p.), 2009.

MAPAS BRASIL. Disponível em <http://www.mapas-brasil.com/piaui.htm> Acesso em 27 jun. 2012

MOLETTA, V.F. Turismo Rural. 2. ed. Porto Alegre:SEBRAE/RS, 2000.

MOREIRA, A M.; MAVIGNIER, D.S. Conhecendo História e Geografia do Piauí. Parnaíba: Gráfica Ferraz, 2007. 
PEARCE, D.G. Geografia do Turismo: fluxos e regiões no mercado de viagens. São Paulo: Aleph, 2003.

REDETRAF - Turismo na agricultura familiar. Disponível em <http:// www.redetraf.com.br/r-rede-traf.asp $>$ Acesso em 27 jun. 2012.

RUSCHMANN, D V.M.. Turismo e Planejamento Sustentável: A proteção do meio ambiente. 9. ed. Campinas: Papirus, 2002.

SEBRAE Paraná (2011). Desenvolvimento Rural - Associativismo e cooperativismo. Disponível em <http://www.sebrae.com.br/customizado/desenvolvimento-territorial/temasrelacionados/associativismo-e-cooperativismo >. Acesso em 08/12/2011.

SETUR Paraná (2007). Turismo Rural no Paraná [pdf]. Disponível em <http:// www.agricultura.pr.gov.br/arquivos/File/deagro/progturisrural.pdf> [último acesso em 07/12/2011].

THOMAZI, S. Clusters de Turismo. São Paulo: Aleph, 2006.

TULIK, O. Turismo Rural. São Paulo: Aleph, 2003.

ZIMMERMANN, A. Turismo rural: um modelo brasileiro. Florianópolis: Editora do Autor, 1996.

Ricardo Gomes Ramos: Universidade Federal do Paraná, Matinhos, PR, Brasil.

Email: ricardo0219@hotmail.com

Link para o currículo Lattes: http://lattes.cnpq.br/3920356245716937

Valéria de Morais Costa Moura: Faculdade Piauiense, Teresina, PI, Brasil.

Email: valeriademorais_89@yahoo.com.br

Link para o currículo Lattes: http://lattes.cnpq.br/6297718007528736

Ermínia Medeiros Macêdo: Universidade Federal do Piauí, Teresina, PI, Brasil.

Email: erminia.medeiros@hotmail.com

Link para o currículo Lattes: http://lattes.cnpq.br/9342170014194913

Data de submissão: 27 de junho de 2012

Data de recebimento de correções: 10 de novembro de 2012

Data do aceite: 10 de novembro de 2012

Avaliado anonimamente 